\title{
Developing and Assessing a Music Technology and Coding Workshop for Young Women
}

\author{
Ms. Abigail Jagiela, University of St. Thomas \\ Jenna Laleman, University of St. Thomas
}

Jenna is a senior at the University of St. Thomas, finishing up her Bachelor's Degree in Elementary Education and STEM Education with a minor in Psychology. Jenna collaborates with the Center for Engineering Education to create outreach curriculum. She works in her university's Playful Learning Lab which focuses on engaging students of all ages in hands-on, innovative engineering education, especially focusing on reaching the underrepresented within the STEM fields. Jenna also leads the University's STEPS (Science, Technology, and Engineering Preview Summer) Program, developing the curriculum, leading the staff, and working as the primary researcher.

\section{Ms. Paige Huschka, University of St. Thomas \\ Dr. Deborah Besser P.E., University of St. Thomas}

Dr. Besser is the chair of civil engineering and the director of the Center for Engineering Education at the University of St. Thomas. Previous experience includes faculty positions in diverse universities where she has taught a variety of coursework including steel, timber, concrete and masonry design, construction management, engineering economy, engineering design/graphics and engineering education. Prior to teaching, Dr. Besser, a licensed engineer who holds a PhD in education and MS and BS in civil engineering, was a design engineer with HNTB-CA, where she worked on seismic retrofits and new design of high profile transportation structures.

\section{Dr. AnnMarie Thomas, University of St. Thomas}

AnnMarie Thomas is a professor in the School of Engineering at the University of St. Thomas where she is the director of the UST Center for Engineering Education. Her research group, the Playful Learning $\mathrm{Lab}$, focuses on engineering and design education for learners of all ages. 


\title{
Code + Chords: Teen Tech- A Program Combining Music and Coding for Young Women
}

\begin{abstract}
This paper discusses a program offered at the University of St. Thomas that promoted interest and confidence in the fundamentals of circuitry and computer programming for girls 13-18 years old. The Code + Chords: Teen Tech program aimed to increase knowledge, awareness, and interest in STEAM (science, technology, engineering, art, math) concepts by exposing students to principles of coding and a variety of new technologies in combination with aspects of music. The program emphasized the creativity and design aspects of engineering, the A in STEAM, which are often excluded from STEM outreach programs. Data was collected through brief Google Surveys, weekly student journals in SeeSaw, and program leader observations. These provided feedback on the program and allowed for an evaluation of the program's impacts in key areas as outlined by the research question; "How does a program that combines arts and engineering impact middle and high school girls' interest in STEAM and their confidence in their own programming and skills and knowledge through a hands-on, out-of-school workshop which focuses on music and coding?"
\end{abstract}

\section{Program Overview}

Code + Chords: Teen Tech (subsequently referred to as C+C:TT) consisted of five 3-hour workshops on consecutive Saturday mornings. The program ran twice with two different groups of participants, the first beginning in January of 2017 and the second in April of 2017. There were 22 participants total in this study. All students attending the program were invited to participate in the research. $\mathrm{C}+\mathrm{C}$ :TT focused on providing hands-on lessons about the fundamentals of circuitry and basics of computer programming through the lens of music, taught by four college-aged student researchers. The program commenced by encouraging students to utilize these newly-learned skills and tools in a collaborative final project, combining what they learned from each of the prior sessions. Participants consisted of a diverse group of 7th-12th grade girls who expressed an interest in exploring the STEAM fields and/or in furthering their knowledge and confidence in computer programming. Major areas of this program included circuitry, coding, the combination of music and technology, and collaborative challenges. The overall goals of the program, with upheld focus on increasing interest, knowledge, and confidence in STEAM, were as follows:

1. Increase young women students' interest levels in STEAM fields

2. Provide an opportunity for young women to engage in coding and use coding as a platform for future STEAM inquiry in college and beyond

3. Increase student self-confidence and critical thinking skills in STEAM/coding

4. Incorporate coding into a topic in which students are interested in and experience daily such as music

5. Help students draw connections between their interests, passions, and STEAM disciplines 


\section{Rationale for the Program and Literature Review}

When assessing the global proportion of STEM professional positions between men and women, it is far from equal. According to the National Science Foundation, men far outnumber women in computer science and engineering fields (NSF Digest, 2013). Aware of this gender gap, President Barack Obama's administration launched Educate to Innovate in 2009, a campaign striving to help close this STEM gender gap through education, providing more accessible opportunities for all students to participate in and learn about STEM subjects. The C+C:TT program followed this initiative, as it aimed to increase knowledge and awareness of STEAM concept by incorporating art in conjunction with other STEM fields and topics. Promoting STEAM rather than STEM highlights the importance of creativity and design in these fields, which are often perceived as more technical-based. This focus often attracts more young women, propelling them into potential engineering and computer science careers later in life by promoting opportunities for early STEAM education which work to close this stark gender gap.

Creativity and music were at the forefront of each element of the program. According to a 2013 study completed at Drexel University, students consistently perform higher in their overall education when they are exposed to the arts (Gregorio, 2013). This finding was reinforced in a study performed by Michigan State University. When reviewing education history of honors graduate students, the study found that nearly 93\% of STEM honors students had participated in musical education in the past (Brockmann, 2015). Based off of this research, it was believed that participants interest in the curriculum would be heightened because not only are art and music an important part of teens' day-to-day lives, but the inclusion of such topics provided varies educational benefits.

Girls were specifically chosen as participants because of the circumstantial and societal barriers surrounding women taking a role in STEAM fields. Countless research studies have documented the underrepresentation of women in science, technology, engineering, and math (STEM) fields linking this issue back to the "attitudes and behaviors of girls from elementary school through graduate studies" (White \& Wasburn, 2006). Early on in women's educational life, they experience "stereotypes, gender bias, and the climate of science and engineering" in their schools that ultimately inhibit their progress within STEM fields (Hill, 2010) and discouraging women from continuing to learn about some of these topics. Because of this, C+C:TT's ultimate goal as a program was to ignite a curiosity in participants that might not be unveiled in traditional education. With the ever-growing want and appreciation of exposing youth to the field of computer science and programming, this program provided an opportunity for teen girls to gain hands-on experience in these fields.

\section{Program Overview and Evaluation}


Each session was dedicated to introducing program participants to the topic of circuitry and the process of programming. The first three sessions were focused on teaching participants different aspects of technology; Scratch, littleBits, Makey-Makey, Squishy Circuits, Processing, and virtual reality. The final two sessions were centered around completing an open-ended group project relating to the technology students had been exposed to during the program. The end of the final session was set aside for a program showcase where friends, family, and St. Thomas graduate students came to view projects that participants had created. The program was run by two undergraduate engineering students and two undergraduate STEM education students.

Every day began with brainteasers and an icebreaker, usually outside on campus. These were implemented in order to help participants feel more comfortable with each other, hopefully increasing their confidence in participating and asking questions during the sessions. Students also watched an OK Go music video each week to help spark ideas of creative ways to combine music and technology. One student mentioned these videos when discussing her ideas for the final project as she remarked, "I want to do a final project of a video done like OK Go's videos." Another similarly shared, "For the Final Project, I'd love to make a Rube Goldberg Machine, music video (like OK Go), or a combination of both."

The first session was dedicated toward the introduction of the visual programming language Scratch and the electronic circuit tool Makey-Makey. Before using these tools, students were presented with an engineering design process in order to help initiate design thinking and simplify the problem-solving process. To introduce Scratch, participants completed basic tutorials online. Participants were encouraged to participate in the online tutorial called "Make Music" which emphasized the musical applications of Scratch as a programming language. A "make-your-own" instructional activity asked participants to use their basic Scratch skills to create their own cat and mouse game. Although given guidelines, most students individualized their games in different ways: some added different characters, changed the music, or even designed a way to keep score. After learning Scratch, students were introduced to Makey-Makey. Makey-Makey is a circuit board that connects to a computer via USB and can replace certain elements of the keyboard with different conductive elements which then take on that key's function. Students were able to participate in a demonstration of this tool using fruit instead of keyboard keys and conductive dough as keys on an online piano program. Scratch and MakeyMakey work well together, so for the final project of this day, participants were grouped in teams and challenged to create an instrument which combined these two tools. The teams of students were told they would need to create physical instruments using recycled materials and a combination of non-conductive and conductive materials. These conductive materials would be used to work in conjunction with their Makey-Makey to establish a circuit similar to the earlier inquiry opportunities. Students were also told that the sound output by the instrument would need to come from a program that they created in their teams within Scratch. During this first day, students brainstormed, planned, and began to create these instruments within their groups. 
The second session was a continuation of the first as students completed and presented their instruments. Participants were given project expectations of the instrument as well as time and material constraints: required to use Scratch, Makey-Makey, and had to have a sound output of music, whatever way that was interpreted as shown in Image 1. The rest of the requirements and project details were open-ended, spurring a wide variety of finished instruments. These included traditional instruments such as pianos, guitars, and flutes, and unconventional instruments including a drum set which made barnyard animal sounds and a musical bookshelf. Students in both sessions offered positive feedback about this day. Many discussed enjoying the activity or considering it their favorite part of the program. When asked why, students often noted they liked being provided some direction but also enjoyed that the task was left open-ended so they could choose the creative direction to steer their project. One student explained, "I really enjoyed being able to connect coding with music, and I felt that this activity was the most connective between the two." When asked, which of the following was your favorite activity?, $50 \%$ of students selected the Musical Instrument Challenge as their favorite, as shown below in Figure 1.

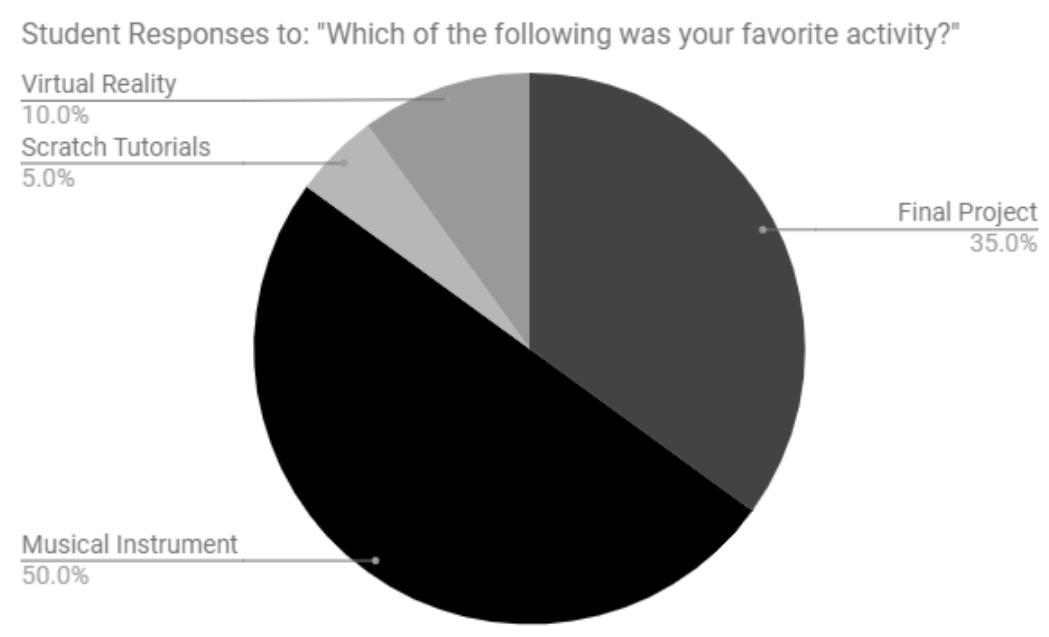

Figure 1: Pie chart of student responses to the question which of the following was your favorite

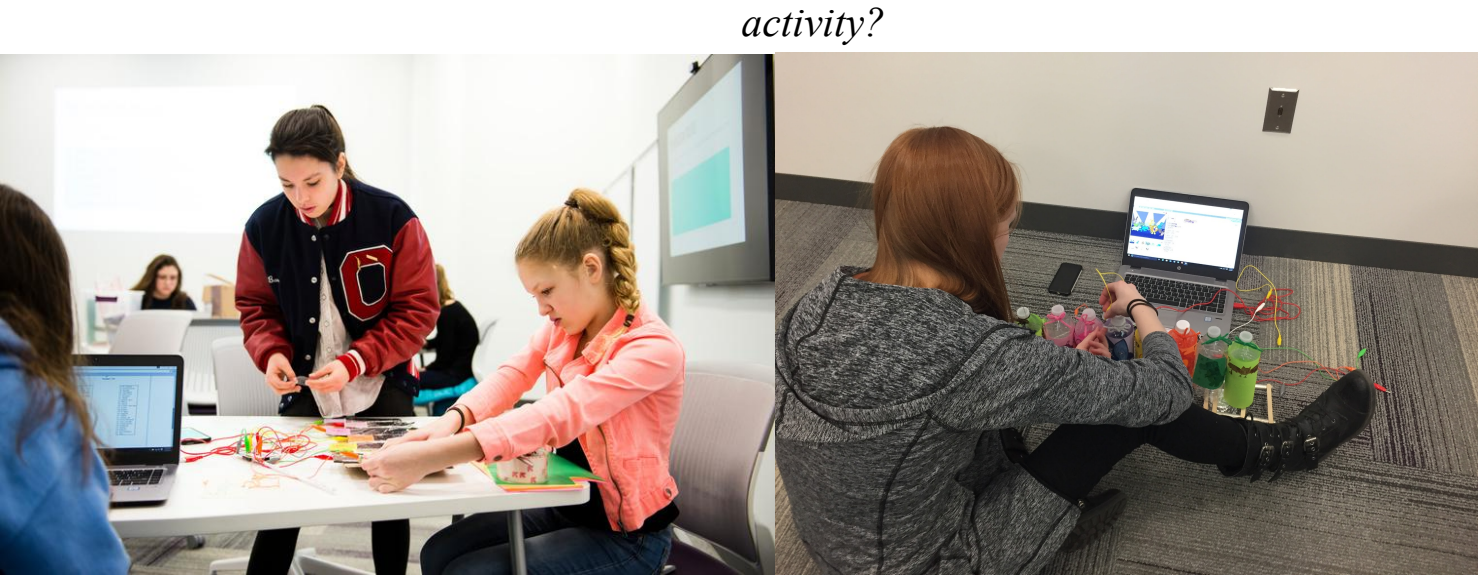


Images 1 and 2: Images of participants assembling their instrument with the use of Scratch and Makey-Makey

The third session introduced additional technology to the participants. They were shown a video showcasing The University of St. Thomas's Playful Learning Lab and their work with an acapella group, Cantus, on the project Code + Chords. This team collaborated to create a program which visualizes real-time music with different modules, including a software that changes shape and color based on the pitch, frequency, and amplitude of each singer's sound. The project was inspiration for the coding station during this day and the initial works of the program in general, which is why this program shares a similar name. During the third session, participants split into four groups and engaged in mini-stations that introduced them to a variety of music and technology topics; the University of St. Thomas's STELAR virtual reality, Squishy Circuits, littleBits, and coding in Processing. At the virtual reality station, participants tried Google Paintbrush, a virtual reality program that lets the user paint in 3D, and an exploratory video game. At the Squishy Circuits station, students learned how to physically make a circuit with conductive playdough and LED lights, tying into the topic of circuits from the first week. LittleBits are conductive building pieces, similar to Legos, which snap together to create music or noise-making circuits. Students worked with these tool as as they either followed an online guidebook of projects or inquired their own project ideas as shown in Image 2. Finally, the coding station began as a large-group introduction with a chance for students to individually continue during their station time.
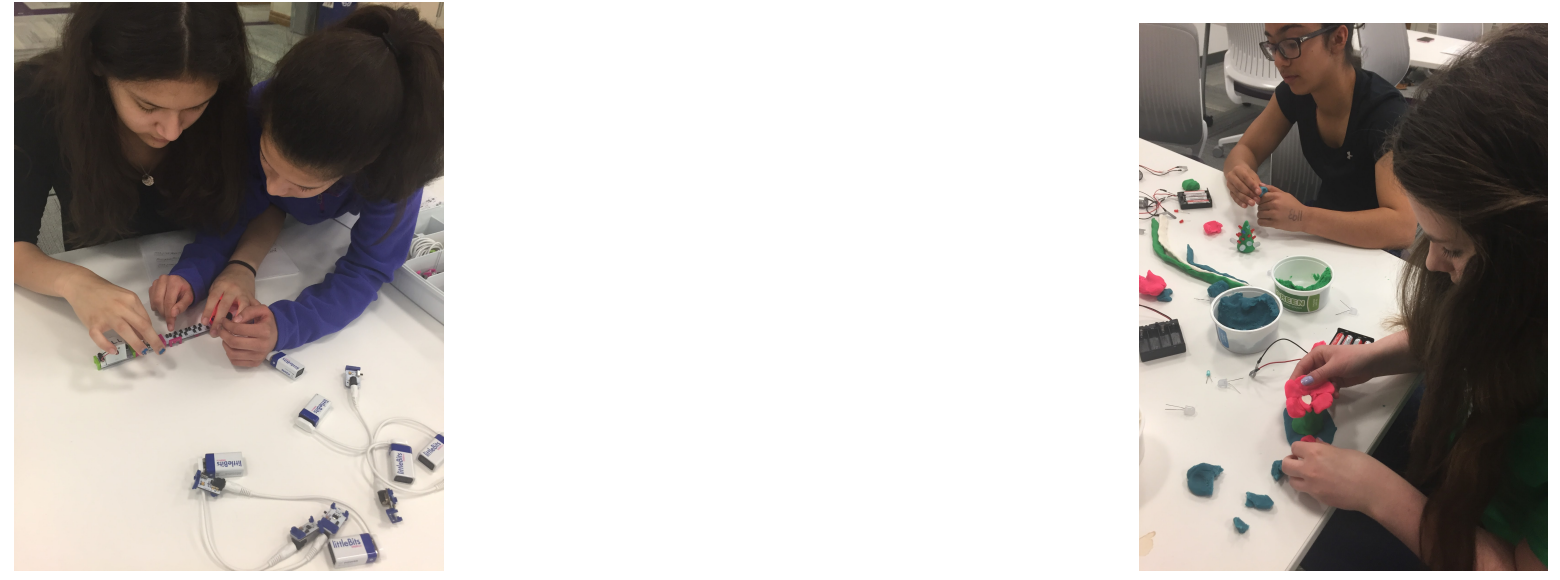

Image 3: (left) Participants experimenting with littleBits as a way to experience the fundamentals of circuits. Image 4: (right) Participants working with Squishy Circuits

The coding project differed from the first program in January to the second program in April. Both programs used Processing, an open-source computer programming language that is frequently used when attempting to display visual arts and teach those not familiar with programming the basics of the tool. In the January program, students were given line-by-line directions which they individually typed to create their own play/pause button through Processing. However, there were several issues with this activity: students had problems opening 
music files in the library, and the way in which this was taught left students simply copying down code. This proved to be a time-consuming task, and did not allow them to learn why they were copying down each certain element or how the code actually worked. Because of these struggles, the third session in April had a different coding project. Connecting with the Cantus project more closely, participants in the second program offering were given written lines of code with blank spaces for them to insert values within Processing. This module was used to visualize real-time sound and explained to participants what each part did. Participants could individually insert components into the code and investigate how their changes affected the output. The change in this activity improved the student's experience with coding immensely and went more smoothly than the first session. Overall, these stations made for an enjoyable, wellreceived day: the girls appreciated the exposure to the different resources, and especially liked the virtual reality. Many wondered how they could incorporate the coding and music we were learning into it in the future.

The fourth session began with completing the exploration of the four activities from the previous week, ensuring that each student was able to participate in all of the activities. After this, participants were introduced to their final project. The goal of this project was to combine any or all of the aspects students had been exposed to in the program and use them to create something involving technology and music. This goal was purposefully broad to inspire creativity. Students were asked to brainstorm ideas and were grouped based on project interest. The engineering design process was reiterated through these projects as students were given a guided timeline to work through the steps of brainstorming, planning, and creating. The planning component of the design process was heavily stressed, especially with a limited project creation timeline. When the groups completed this step of the design process, they were free to begin designing, building, and testing their projects as shown in Image 4. This continued through the last session of the program.

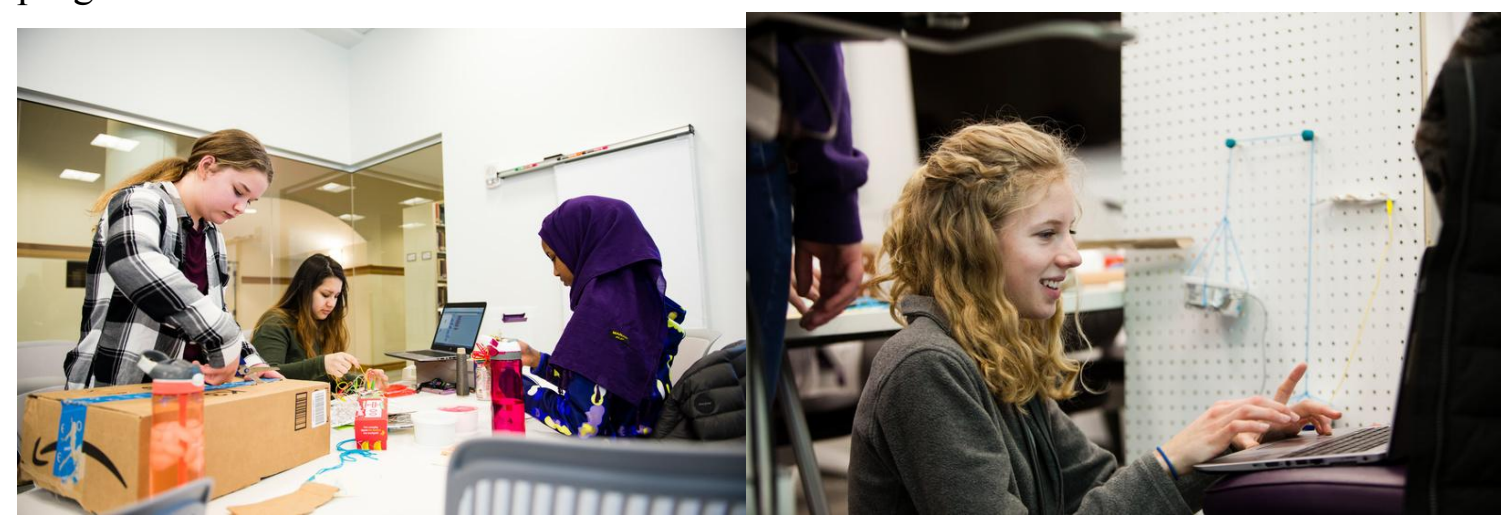

Image 5: (left) Students collaborating to complete their final project. Image 6: (right) A participant combining her previous sessions knowledge of Scratch and Makey-Makey to code her chain reaction machine for the final project part of the program. 
The fifth session's time was used for participants to work on their final projects. Parents, friends, and university graduate students were invited to the last half hour of the session to view the girls' final projects and presentations. Parents loved this aspect of the program, saying it was rewarding to see them proud of their daughters. Students also noted really enjoying the final project as one stated, "it offered a lot of freedom and left room for creativity and whatever my group felt like doing." A second student shared, "We got to be really creative and combine everything we had learned over the course of the program." A third student also mentioned, "This was my favorite activity since it required us to use the design process." Final projects included a Guitar Hero game programmed in Scratch and connected to a Makey-Makey, a chain reaction musical machine, and a band with coded graphics.

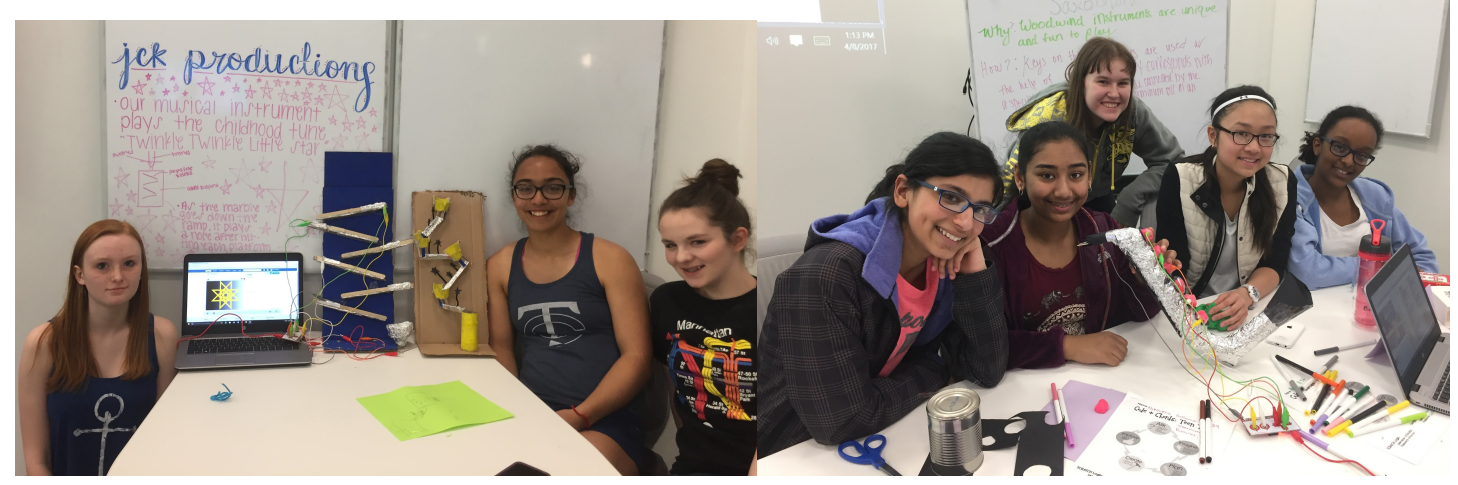

Image 7: (left) A group's final project presented to family and friends on the last day of the the program. Image 8: (right) A group's final project with implementation of Scratch, Makey-Makey, and the instrument challenge.

\section{Research Method}

All program participants were invited to participate in the research study. Of the students attending the two sessions, 21 students agreed to be research participants with 9 of these students attending the first program in January and 12 attending the second program in April. Using Google Forms, research participants filled out 10-15 minute anonymous surveys before and after participating in this program in order to assess student interest levels, attitudes, and knowledge about music and coding areas as well as how these may have changed over the duration of the program. The post-program surveys also offered an overall evaluation of the program with questions asking for participant feedback and growth in content areas. The pre-program survey consisted of six short-answer questions and ten Likert-scale based questions. The post-program surveys consisted of eight short-answer questions and the same ten Likert-scale based questions. Participant answers were recorded through a number randomly assigned to each student which allowed researchers to compare this data while still keeping the responses anonymous. Students additionally filled out daily online journals at the end of each session through a platform called SeeSaw. These served as a way for students to reflect on what they enjoyed and learned that day, as well as ask any questions they may have. The entries were semi-structured through prompting questions and statement starters such as "Today I...", "I wonder...", and "Next time, my plan is/I 
would like to..." After the program, researchers analyzed responses to understand the impacts of the program and look for areas of future growth in the development of this program.

\section{Research Analysis and Data Discussion}

The research question chosen to embody the main purpose of the program was: "How does a program that combines arts and engineering impact middle and high school girls' interest in STEAM and their confidence in their own programming and skills and knowledge through a hands-on, out of school workshop which focuses on music and coding?" Five main program goals were developed in order to help better understand the impact the program had on student interest, confidence, and knowledge as well as assess the quality of the program.

Through surveys, researchers were able to better understand participants' knowledge, interests, and attitudes in regards to circuitry, coding, programming, music, and STEAM. Of the research participants, $35 \%$ identified with a racial minority. There were four seventh-grade students, six eighth-grade students, three ninth-grade students, six tenth-grade students, and two eleventhgrade students within the research study. Participants also expressed an interest in music as 66\% indicated playing an instrument and $57 \%$ being involved in choir. Below are the outlined program goals and both quantitative and qualitative data used to evaluate the program's achievement within these five key areas.

Goal \#1: Increase young women student interest levels in STEAM (science, technology, engineering, arts, and mathematics) fields

Below is a discussion of trends in student responses to the statement I could see myself pursuing a career in engineering. 


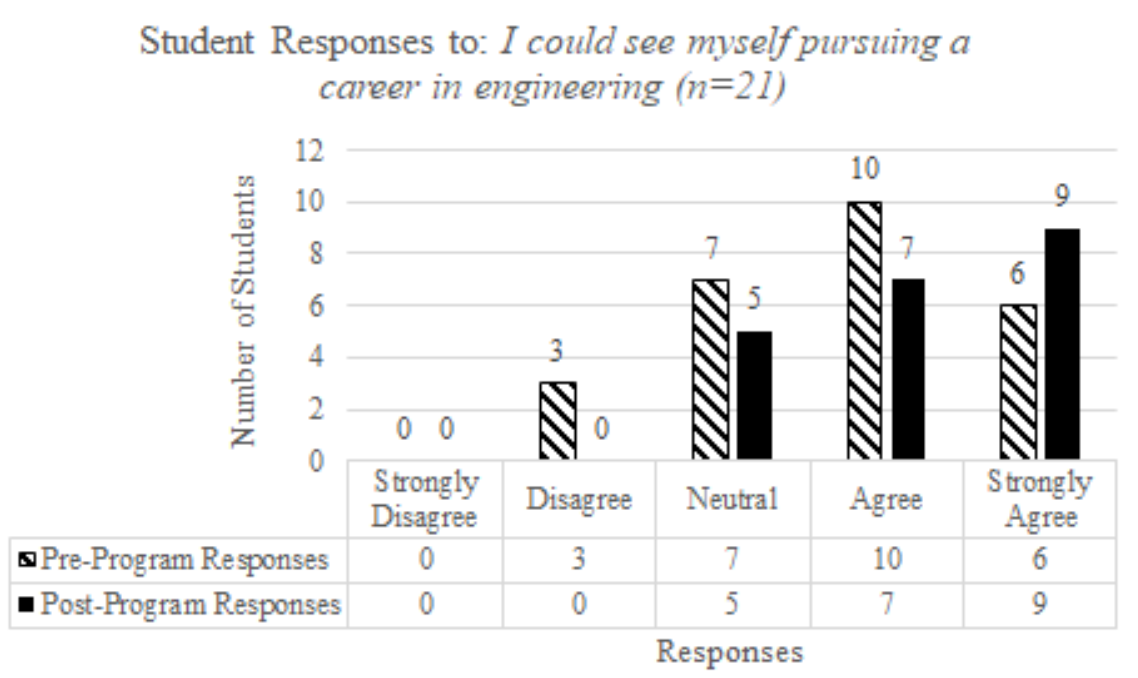

Figure 2: Bar graph comparing pre-program and post program student responses to the statement I could see myself pursuing a career in engineering.

As seen in Figure 2, over $75 \%$ of students agreed or strongly agreed to this statement both before and after the program. It is also interesting to note that over $28 \%$ of students answered strongly agree before and after the program. This exposes a weakness of a five-point scale, not allowing for these students to indicate a potential increase in agreement after the program. Overall, we see an increase in students strongly agreeing with this statement while all other response saw a decrease in the number of responses. This leads us the the conclusion that students had a more positive view on their potential future in engineering after the program.

Student journal responses offered additional insight into evaluation of the program's first goal. One student reflected on the program as she wrote in her journal entry, "all in all the program was super fun and I would love to do it again. It helped me really secure that I want to be an engineer when im older." A second student shared an increase in general confidence through this program as she shared how it helped foster growth and learning: "At first I was afraid to ask questions, but now I am really comfortable with the group. I also liked how well they compensated for everyone in the group, I never felt either behind or ahead, which is rare in a large group like this." These responses indicate that the nature of the program and its components contributed to an increase in self-efficacy and interest in STEAM for many students.

\section{Goal \#2: Provide an opportunity for young women to engage in coding and use coding as a} platform for future STEAM inquiry in college and beyond This goal focuses on assessing how the program may impact students' confidence in STEAM. The goal also evaluates interest levels as students were asked questions about their aspirations in STEAM. When asked to respond to the statement, I want to attend college in the future, $100 \%$ of participants chose 'strongly agree' in their post-program survey. Understanding the desire these 
students have for attending college, students were asked to share which fields they may be interested in studying and working in. Students demonstrated their level of agreement with the statement I could see myself pursuing a career in computer science/programming.

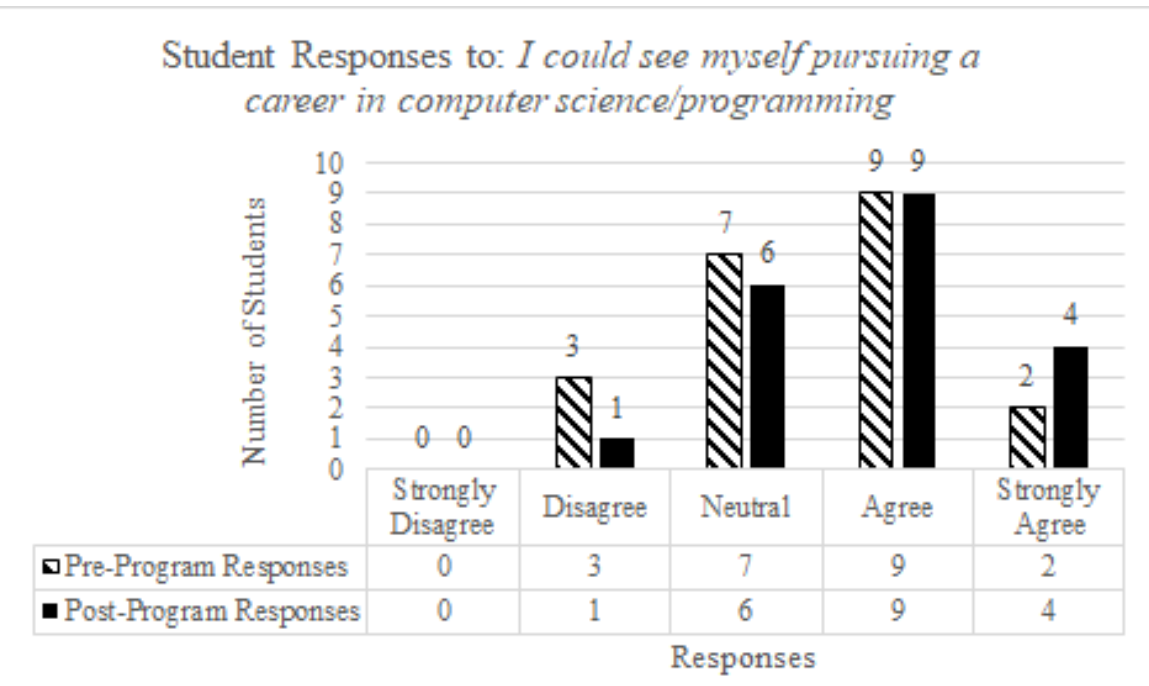

Figure 3: Bar graph comparing pre-program and post program student responses to the statement I could see myself pursuing a career in computer science/programming.

Figure 3 highlights students' changes in their interest in pursuing computer science and/or programming. Overall, data trends are fairly similar between pre-program and post-program responses, with a slight decrease in the number of students disagreeing and a slight increase of students strongly agreeing. The lack of change in responses to this statement leaves the program's overall impact within this area still in question.

This second goal can be investigated by looking at responses to another related question about coding. 


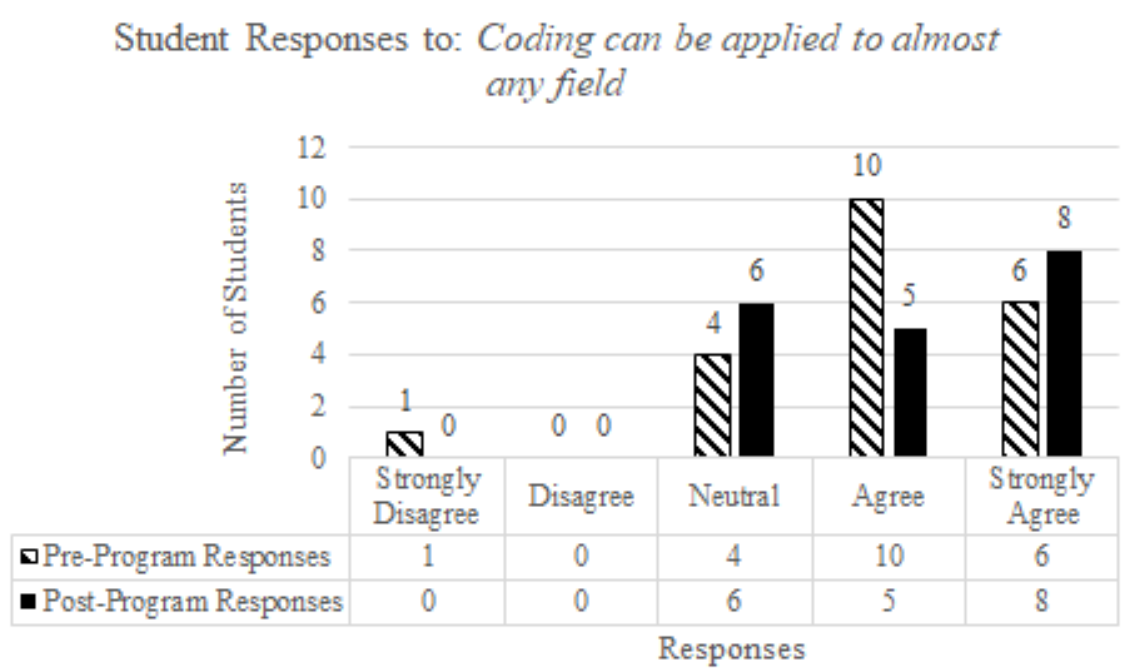

Figure 4: Bar graph comparing pre-program and post program student responses to the statement Coding can be applied to almost any field.

In both the pre-program survey and post-program survey shown in Figure 4, almost all students felt neutral about or agreed with this statement. Changes between pre-program and post-program responses exist but are not significant, especially with such a small sample size. Because of this, it seems that conclusions cannot be drawn as to if the program changed overall perceptions of the applications of coding to almost any field, but rather that both before and after the program students tended to agree with the statement. While our data did not lead us to any conclusions about impacts on creating this platform, the general nature and structure of the program lends to this goal. The program itself offered attendees opportunities to engage in coding. Longitudinal work would need to be done in order to truly understand what the program's impacts are in their future STEAM and coding aspirations.

\section{Goal \#3: Increase student self-confidence and critical thinking skills in STEAM/coding}

Students were encouraged to engage in a self-reflection of their skills and knowledge in a few content areas through survey questions. Below displays student responses to the statement $I$ think I could explain to a friend how a simple circuit works. 


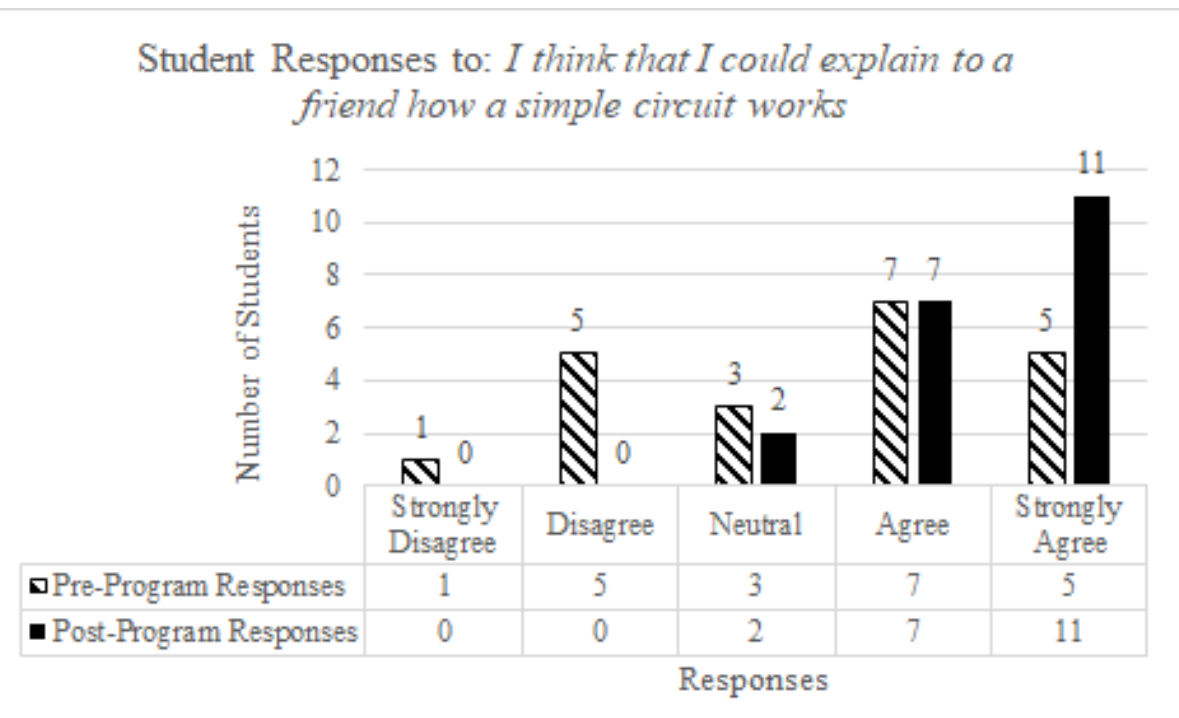

Figure 5: Bar graph comparing pre-program and post program student responses to the statement I think that I could explain to a friend how a simple circuit works.

As shown in Figure 5, all students either agreed with or felt neutral about this statement after the program. Additionally, the number of students who strongly agreed with this statement following the program more than doubled. Because this statement opens with "I think I could..." it allows students to engage in a self-evaluation, judging some of their confidence in their own abilities. The second half of the statement deals with the conceptual understanding and application that students felt they possessed when responding to the statement. The results, as mentioned above, lead to the conclusion that the program increased students' confidence and knowledge in circuitry as this data displays a great increase in student agreement with the statement.

Students commented on their personal growth in circuitry knowledge through journal reflections as well. One individual explained, "Today I learned a little bit about circuits and how they need a ground wire and have you be connected to something conductive." This response connects with the demonstration shown to students as she used the terms "ground wire" and "conductive", things addressed when showing students how to create a circuit using the Makey-Makey tool. When reflecting on her instrument challenge, another student articulated how this helped her understand circuitry better: "I learned how the aluminum connected the current, so we had to put paper so it wouldn't conduct the electricity and use all the keys at the same time. It made me think about how to make it without the wires so it would look even more real." This individual learned through the activity that if conductive things are touching, the electricity runs through all of them, but if she wanted to create separate notes for her instrument, she would need to divide these notes with insulating materials.

The goal of developing self-efficacy and critical thinking skills can be investigated more deeply through an examination of whether the participants' confidence in their ability to program 
increased. This can be evaluated based on their responses to the statement I can create a simple coding program from scratch with guidelines. While the question itself evaluates students' technical skills, the way that the statement is worded prompts students to reflect on their own abilities and therefore was included in our discussion on evaluating efficacy.

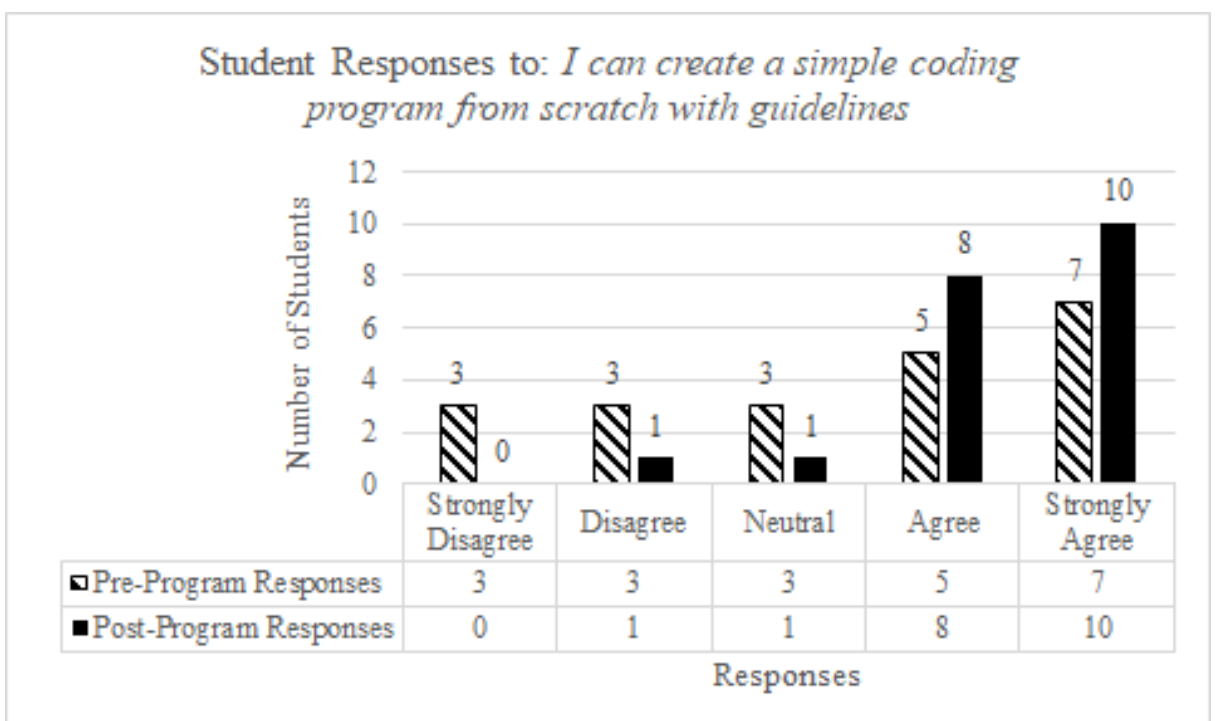

Figure 6: Bar graph comparing pre-program and post program student responses to the statement I can create a simple program from scratch with guidelines.

This figure shows that more students agreed and strongly agreed with the statement after this program, thus highlighting a potential shift in both technical ability and confidence in this area. While $66 \%$ of pre-program responses were strongly disagree, disagree, or neutral, over $85 \%$ of students responded that they felt confident in their coding abilities by indicating a response of agree or strongly agree with this statement after the program. This drastic change indicates newly-instilled coding skills as well as recognition of and confidence in these skills.

Goal \#4: Incorporate coding into a topic in which students are interested in and experience daily, such as music

This goal was addressed through the structure and focus of the program. Through each of the lessons, challenges, and activities, students combined technology and music. The coding in Scratch involved coding sounds for their instrument and the coding in Processing allowed students to work with programs inspired by the Code + Chords and Cantus work. The musicdriven focus of this program was evident each week as a way to bring STEAM into an area which students were passionate about.

Goal \#5 Help students draw connections between their interests, passions, and engineering 
Through this goal, researchers were able to better understand how student interest levels were impacted by the program. To assess this, students responded to the statement Programming involves more than just words and numbers on a screen.

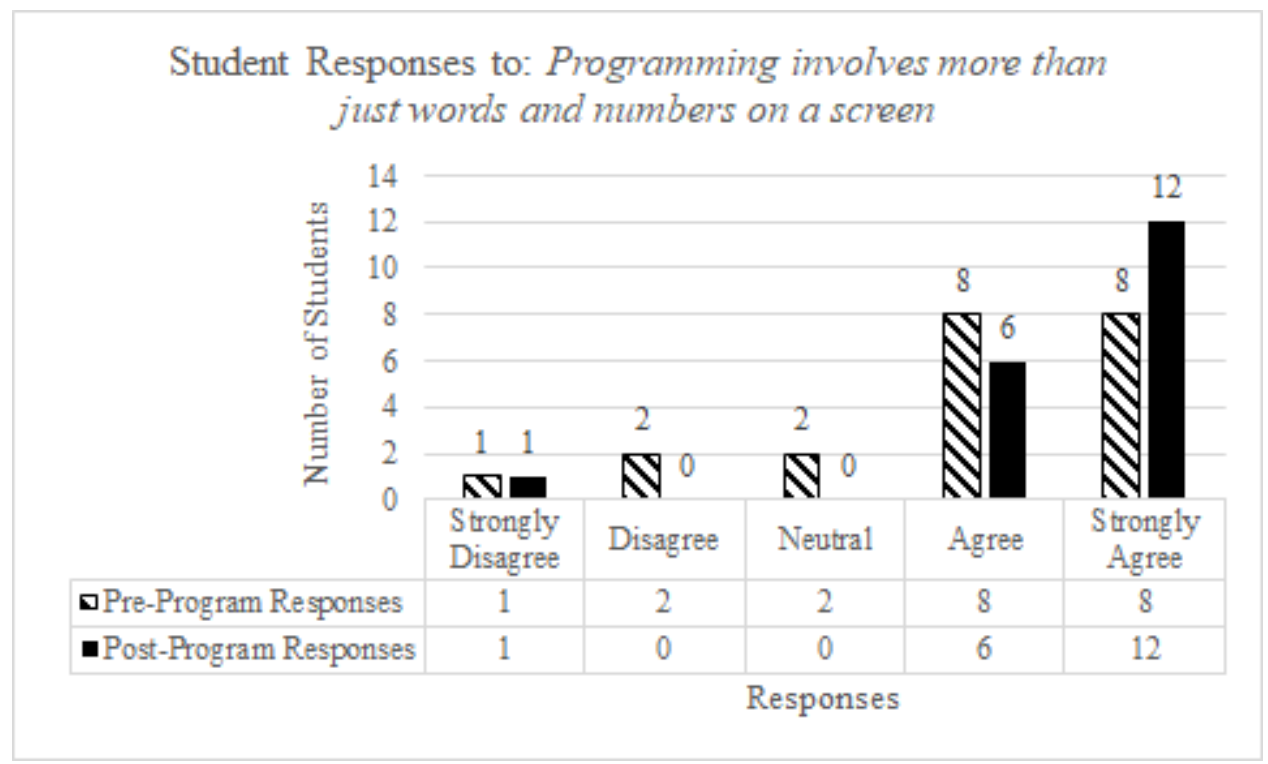

Figure 7: Bar graph comparing pre-program and post program student responses to the statement Programming involves more than just words and numbers on a screen.

The data in Figure 7 reveals that the number of students who strongly agreed with the statement after engaging in the program significantly increased. While $25 \%$ of students did not agree or strongly agree with this statement before the program, $95 \%$ did. This level of agreement indicates that students left the program with a broader definition of programming.

The goal of allowing students to make personal connections was also fostered through the openended nature of the program, particularly when it came to the two main projects: the "Instrument Challenge" and "Final Project". Students commented on their enjoyment of this flexibility. One shared that "My favorite part of the day was creating our projects because it allowed us to do whatever we wanted and be creative." while another noted, "I liked the freedom to design whatever instrument we wanted and then the hands-on part of building it." These remarks indicated that students found the activities to give them freedom to connect their personal interests with what they learned through this program, an enjoyable aspect of the program.

\section{Research Summary}

After analyzing all of the data, this program made gains in most of the initial goals, developing an encouraging, educational, and fun experience for young women that brought awareness to the STEAM fields. Ultimately, these goals connected with the research question looking at the program's impact on interest levels, confidence, and knowledge in STEAM. Overall, students entered the program with an interest in STEAM, but most indicated an increase in interest and 
confidence after the program. Their attitudes were often more open to broader applications of STEAM and coding, and positive in their feelings towards a program of this nature. Lastly, their knowledge was heightened in the basics of circuitry and programming as they were exposed to these areas and new pieces of technology throughout the program.

\section{Thoughts for Next Time}

In the post-program surveys for both sessions, there were multiple girls that spoke about the first Processing activity: creating a play/pause button for a music library. Program developers agreed that this activity needed to be revised, as most of this day was spent trying to figure out the technology, rather than teaching the participants the activity itself. Based on initial feedback, we updated this activity for the next session in April as aforementioned. We observed that the second session expressed greater excitement and sparked a larger number of questions, conveying the girls' curiosity. It was difficult to find a balance between creating an activity that would not be boring for those who have used coding programs before, but not too hard for those that had not. The sound-visualization activity was a step in the right direction, but we feel we need to shape this lesson plan better to encourage more exploration and incorporate more advanced coding skills for future use, especially since coding is a key component of the program.

The type of coding in Processing seemed to resonate more with participants than the drag-anddrop nature of Scratch. Two participants spoke to this, saying "I would try to lean away from Scratch and instead talk about more realistic programming sites like JavaScript or MatLab" and "I would introduce us to more coding in programming, like the play pause button. we should do more of that." In the second session, there was only positive feedback on the coding exercise, which supports the conclusion that most participants liked the more "realistic" coding in Processing. We believe that Scratch is a great way of introducing coding to students, especially those with no coding experience. However, next time we would like to spend more time on projects in a programming language that could be used as students further their skills in coding.

It was evident from responses that we need to provide not only more time for the final projects, but possibly longer session times in general. When asked what students would change about the program, $30 \%$ of their suggestions were to have more time. To do this, we could make the program six sessions instead of five, adding another day to further develop their final project.We could also increase the time of each session to four hours rather than three, allowing more time to fit lessons in that develop more complex coding skills and use advanced programming languages. These modifications would enable us to provide more advanced coding knowledge and alleviate some stress that the final project time frame caused.

We found that the large age range in the group moderately worked, but we feel that a smaller age group would be best - for example, a 13-15 year old group and a 16-18 year old group. The participants connected, but there was a noticeable difference between the maturity of the younger 
versus the older which could have hindered the program. If participants were separated into groups closer to their own age and maturity, it might have been easier to become more comfortable and willing to participate with each other. With these factors increased, the program might have been more beneficial to each participant. In the next program, we plan to implement these changes.

Overall, we received positive feedback from students and parents at the end of each session. Many parents commented on how their daughter would come back from the program excited about what they learned. Students told us how they took the new skills and information and brought it to their classroom to discuss with a teacher. These positive remarks demonstrate that our first two sessions of this new program were impactful, but there are still areas in which the program can improve. 


\section{References}

Brockman, J. B. (2015). WAVES: An integrated STEM and music program for fifth grade students, ASEE Annual Conference, Seattle, Washington, June 2015.

Gregorio, J. et al. (2013). Music technology as a vehicle to STEM/STEAM for high school students. ASEE Annual Conference, Atlanta, Georgia, June 2013.

Head, L.M. (2011). Signals, systems, and music: General education for an integrated curriculum. ASEE Annual Conference, Vancouver, BC, Canada, June 2011.

Hill, C. (2010). Why so few? Women in science, technology, engineering, and mathematics. Washington, DC: American Association of University Women.

National Science Foundation (2014). Women, minorities, and persons with disabilities in science and engineering. Alexandria, VA.

White, K., \& Wasburn, M. (2006). A protocol for evaluating web based resources to interest girls in STEM careers. ASEE Annual Conference, Kansas City, MO, June 2006. 